\title{
Modeling the heat transfer by conduction of nanocellular polymers with bimodal cellular structures
}

\author{
Victoria Bernardo ${ }^{\mathrm{a}, *}$, Judith Martin-de Leon ${ }^{\mathrm{a}}$, Javier Pinto ${ }^{\mathrm{a}}$, Raquel Verdejo ${ }^{\mathrm{b}}$, \\ Miguel Angel Rodriguez-Perez ${ }^{\mathrm{a}}$ \\ ${ }^{a}$ Cellular Materials Laboratory (CellMat), Condensed Matter Physics Department, University of Valladolid, Valladolid, Spain \\ ${ }^{\mathrm{b}}$ Institute of Polymer Science and Technology (ICTP-CSIC), Juan de la Cierva, 3, Madrid, 28006, Spain
}

H I G H L I G H T S

- A model to predict the thermal conductivity of nanocellular polymers is presented.

- This model applies to nanocellular materials with non-uniform cellular structures.

- The thermal conductivity of bimodal systems with nanometric cells is predicted.

- The model is validated using experimental results of real bimodal systems.

- It can be also applied to nanocellular polymers with wide cell size distributions.

\section{A R T I C L E IN F O}

\section{Keywords:}

Nanocellular polymer

Thermal conductivity

Modeling

\begin{abstract}
A B S T R A C T
Nanocellular polymers are a new generation of materials with the potential of being used as very efficient thermal insulators. It has been proved experimentally that these materials present the Knudsen effect, which strongly reduces the conductivity of the gas phase. There are theoretical equations to predict the thermal conductivity due to this Knudsen effect, but all the models consider an average cell size. In this work, we propose a model to predict the thermal conductivity due to the conduction mechanisms of nanocellular materials with bimodal cellular structures, that is, with two populations of cells, micro and nanocellular. The novelty of our work is to consider not only the average cell size, but the cell size distribution. The predictions of the model are compared with the experimental conductivity of two real bimodal systems based on poly(methyl methacrylate) (PMMA), and it is proved that this new model provides more accurate estimations of the conductivity than the models that do not consider the bimodality. Furthermore, this model could be applied to monomodal nanocellular polymers. In particular, for monomodal materials presenting a wide cell size distribution and at low densities, the model predicts important variations in comparison with the current models in the literature. This result indicates that the cell size distribution must be included in the estimations of the thermal conductivity of nanocellular polymers.
\end{abstract}

\section{Introduction}

Buildings represent the largest energy-consuming sector in the global economy with more than one-third of the energy expenses. Therefore, they are responsible for more than one-third of global carbon emissions [1]. With the growth of the population predicted for the next decades, the energy used in buildings is also set to increase sharply $[1,2]$. Most of this energy is used in conditioning indoor spaces, so its use could be drastically decreased using more efficient thermal insulation systems.
Cellular polymers are commonly used in house insulation [3-5]. Several factors contribute to their good behavior as thermal insulators. First, the very low thermal conductivity of the gas enclosed in the cells. Second, the distribution of the gas in small cells suppresses convention. Finally, the relatively small amount of solid polymer, that also presents a not very high thermal conductivity. Some of the most common cellular polymers currently used for thermal insulation, such as expanded polystyrene (EPS) or extruded polystyrene (XPS), present thermal conductivities in the range $30-35 \mathrm{~mW} / \mathrm{mK}$ at room temperature [6]. These types of foams have air in the cells sometime after their

\footnotetext{
* Corresponding author.

E-mail address: vbernardo@fmc.uva.es (V. Bernardo).
} 
production, and due to this, the previous values of the thermal conductivity are already within the limits of their potential, as the thermal conductivity of air at room temperature is $26 \mathrm{~mW} / \mathrm{mK}$. The thermal conductivity can be reduced by using other gases of higher molecular weight and with lower thermal conductivities that can stay in the cells of the cellular material for long times, such as HFCS or alkanes. For instance, rigid polyurethane foams foamed using cyclo-pentane can have thermal conductivities of around $21 \mathrm{~mW} / \mathrm{mK}$ just after their production and values around $25-26 \mathrm{~mW} / \mathrm{mK}$ several months after production. This is because the thermal conductivity of cyclo-pentane is $12 \mathrm{~mW} / \mathrm{mK}$. However, the use of these gases is in general not environmentally friendly (HFCS) or even they are a serious drawback for the flame-retardant behavior of the materials (alkanes) $[7,8]$.

So, to develop better insulating materials that are at the same time environmentally friendly, new strategies must be followed.

One interesting approach of producing materials with lower thermal conductivity is the use of nanocellular polymers [1,9-11]. As a consequence of their reduced cell size, these materials allow a significant reduction of the thermal conductivity, as high as 2.5 times for lowdensity materials [12]. Several authors have demonstrated the superinsulating properties of nanocellular materials. Most of the work up to know is focused on the characterization of aerogels [13,14], but polymer-based nanocellular materials have also been successfully tested. Notario and coworkers [12] measured the thermal conductivity of nanocellular poly(methyl methacrylate) (PMMA) with different cell sizes, proving the strong influence of the cell size in the conductivity (Knudsen effect). Grassberger et al. [15] demonstrated the same idea in blowing agent free nanocellular PMMA. In the work of Wang et al. [16], a nanocellular polymers based on blends of low-density PMMA and thermoplastic polyurethane (TPU) was shown to present a thermal conductivity as low as $24.8 \mathrm{~mW} / \mathrm{mK}$.

There are theoretical equations to model and predict the thermal conductivity of nanocellular polymers [12,17-19]. However, none of these models take into consideration that cellular materials can present a non-uniform cellular structure, that is, in all these models only the average cell size is used. Then, the previously mentioned works are not suitable for modeling the thermal conductivity of non-uniform systems, such as bimodal cellular structures with micro and nanometric pores. Such systems could be of great interest since the presence of micrometric pores could help to reduce the density, whereas the nanometric cells will decrease the thermal conductivity.

As a consequence of the interest of bimodal structures, also in the micrometric range, there are several works dealing with the production of such materials [20,21]. For instance, Lee et al. [22] produced bimodal PS/silica structures using two different blowing agents, and they investigated in detail the effect of the amount of silica, blowing agent and extrusion conditions in the resultant bimodal structure. In the work of Zhang and coworkers [23], bimodal PS was also produced by an extrusion process with two blowing agents, and they proved that the bimodality enhanced the mechanical and insulation performance compared with PS cellular materials. Arora and coworkers [24] produce bimodal PS cellular materials using a gas dissolution foaming method in which the pressure was released in two steps. In the work of Zeng et al. [25], PMMA/carbon nanotube nanocomposites showed a bimodal cell size distribution due to insufficient dispersion of the particles. Regarding bimodal structures with nanometric pores, Luo and coworkers [26] proved that the addition of silica aerogel to PMMA induced the appearance of a bimodal structure with nanometric pores in the cell walls, that helped to reduce the thermal conductivity compared to the neat PMMA. In the work of Miller et al. [27], microcellular high-density polyethylene (HDPE) was produced with a unique interconnected nanoporous structure in the cell walls. Schmidt at al [28]. proved that a bimodal structure formed by nanometric pores and micrometric ones (obtained by microemulsion template) presented a thermal conductivity that was between the two limits established by the nanocellular structure (obtained by sol-gel) and a macroporous material.

Several of the previously mentioned works proved that the presence of small cells allows reducing the thermal conductivity, but none of them proposed a model to quantify the weight of the different cells in the cell size distribution. About the modeling of the thermal conductivity of bimodal structures, we have only found the recent work of Gong et al. [29]. They proposed a model to calculate the thermal conductivity of microcellular bimodal structures and validated their model using bimodal PS/multi-walled carbon nanotube cellular materials. However, this model only took into account an average cell size of for each population of cells.

In this work, we propose a new theoretical model to calculate the thermal conductivity due to the heat transfer mechanisms by conduction of nanocellular polymers with non-uniform cellular structures. In this model, the cell size of all cells is considered together with the relative volume occupied by each cell, with the aim of considering the relative contribution of each cell size to the global thermal conductivity. Experimental measurements of nanocellular polymers presenting a bimodal cellular structure confirm the validity of the proposed model.

\section{Theoretical background}

The thermal conductivity of a cellular polymer $\left(\lambda_{t}\right)$ can be calculated as the sum of four different contributions [5,30]:

$\lambda_{t}=\lambda_{s}+\lambda_{g}+\lambda_{r}+\lambda_{c}$

Where $\lambda_{s}$ is the conduction through the solid phase, $\lambda_{g}$ is the conduction across the gas phase, $\lambda_{r}$ is the thermal radiation term, and $\lambda_{c}$ represents the convection within the cells. This last term is negligible for cell sizes smaller than $2 \mathrm{~mm}[5,30,31]$. Regarding the radiation term, there are several models to justify its dependence with the cell size in the microcellular range [32,33], but it is known that the models used for microcellular polymers cannot be used for nanocellular materials. As far as the authors know, the only model dealing with the contribution of the radiation in the thermal conductivity of nanocellular materials is that of Wang and coworkers [19], although the calculation of the radiative contribution is purely theoretical and has not been experimentally validated. In fact, there is not yet any experimental data about how radiation propagates in a system the nanometric cells.

Nonetheless, both the microcellular and the nanocellular models predict that the contribution of the radiation becomes only relevant for low relative densities, due to a high fraction of absorbent solid present in the medium and high-density cellular materials. In particular, in the work of Wang et al. [19] it is proved that for cell sizes in the range of $200 \mathrm{~nm}$ to 10 microns and relative densities around 0.25 or greater, the radiation contribution becomes negligible.

Taking into account that the cellular materials used in this work present relative densities above 0.27 and cell sizes in the aforementioned boundaries, we have neglected in all the modeling the possible contribution of radiation. This means that the model proposed is valid for the thermal conductivity by conduction, including both the conduction through the solid and through the gas phases. The values given by the model will be equivalent to the total conductivity when the radiation contribution is negligible, and this would be the case for cellular materials with high or medium densities (higher than around 0.20) as those included in this paper.

To quantify the weight of each contribution, the relative amount of solid and gas phases should be used, that is, the relative density $\rho_{r}$ (defined as $\rho_{r}=\rho / \rho_{s}$, where $\rho_{s}$ is the density of the solid and $\rho$ is the density of the cellular material). Using this idea, the conductivity can be described as [5]:

$\lambda_{t}=\lambda_{s}+\lambda_{g}=g \lambda_{s}^{\prime} \rho_{r}+\lambda_{g}^{\prime}\left(1-\rho_{r}\right)$

Where $\lambda_{s}^{\prime}$ and $\lambda_{g}^{\prime}$ are the thermal conductivities of the solid polymer and the gas inside the cells, respectively, and $g$ is a an efficiency-structural 
factor proposed by Glicksman [30]. This factor has been shown to be close to 1 for microcellular materials with medium/high relative densities (0.3-0.6) [34] and ranging 0.8-1 for nanocellular polymers with medium/high relative densities (0.4-0.65) [12]. In the case of microcellular structures with very low densities (lower than 0.05 ) (i.e., when the cell walls are very thin and the cells have a polyhedral shape), this factor is $2 / 3$, and when the fraction of mass in the struts is also considered in the model, $g$ can have a minimum value of $1 / 3$ for materials with a high fraction of the solid phase in the struts [30].

In a microcellular material, $\lambda_{g}^{\prime}$ is directly the thermal conductivity of the gas inside the pores $(26 \mathrm{~mW} / \mathrm{mK}$ if the gas is air at atmospheric pressure and room temperature). However, when the mean free path of the gas molecules inside the cells is comparable with the cell size, the conduction throughout the gas is significantly reduced, because the collisions among the gas molecules become less probable than the collisions with the cell walls. This effect is well-known as the Knudsen effect [12,35-38]. Once this effect is taken into account, the effective conductivity of the gas $\lambda_{g}^{\prime}$ can be described as $[36,39,40]$ :

$\lambda_{g}^{\prime}=\frac{\lambda_{g 0}^{\prime}}{1+2 \beta K n}$

Where $\lambda_{g 0}^{\prime}$ is the thermal conductivity of the gas inside the pores, $\beta$ is a factor correlating the energy transfer between gas molecules and the structure (varying from 1.5 to 2 for argon and nitrogen [40] and 1.64 being the value for air [36]), and $K n$ is the Knudsen number, defined as:

$K n=\frac{l_{g}}{\phi}$

Where $l_{\mathrm{g}}$ is the mean free path of the gas molecules $\left(l_{\mathrm{g}} \approx 70 \mathrm{~nm}\right.$ for air $[12,17])$ and $\phi$ is the average cell size. For a cell size much larger than the mean free path, the reduction due to the Knudsen effect is not significant, but for cell sizes under the micron, there is a significant decrease of the thermal conductivity. Theoretically, the Knudsen effect is related to the rarefied gas conduction regime $[36,38]$, which starts to play a role for Knudsen numbers higher than $0.01, K n \geq 0.01$ [41]. In other words, this effect starts to become relevant when the cell size is smaller than 100 times the mean free path, $\phi \leq 100 l_{g}$. For a mean free path of $70 \mathrm{~nm}$, this means that the Knudsen effect should be considered when calculating the thermal conductivity of systems with cell sizes smaller than 7 microns.

Combining equations (2)-(4), we lead to the following expression as a first approach to estimate the thermal conductivity by conduction in a nanocellular polymer:

$\lambda_{t}=g \lambda_{s}^{\prime} \rho_{r}+\frac{\lambda_{g 0}^{\prime}}{1+\frac{2 \beta l_{g}}{\phi}}\left(1-\rho_{r}\right)$

Fig. 1 shows the predictions of equation (5) as a function of the cell size for a nanocellular polymer based on PMMA (conductivity of the solid: $211.7 \mathrm{~mW} / \mathrm{mK}$ ) and for three different relative densities. For this plot, the structural factor $g$ was considered as 1 for simplicity. A discussion about the value of $g$ is included below.

This model was proved to be successful in the prediction of the thermal conductivity of nanocellular polymers [12], but it only takes into account the average cell size. Further considerations are needed to use this model to predict the thermal conductivity of bimodal systems or structures with a wide cell size distribution. Our model attempts to complete and improve the previous one to widen its range of application to systems with non-uniform cellular structures.

\section{Model}

To demonstrate the basic concept of the model, we will consider a very simple bimodal system with two distinct populations of cells. This system can be seen as a two-phase system comprising micrometric and nanometric cells, and it is schematized in Fig. 2.a. The cell size

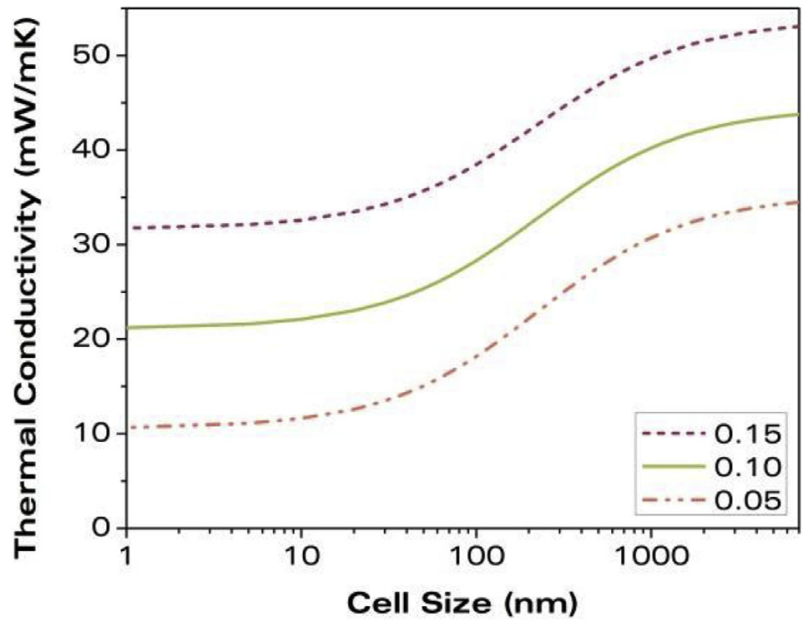

Fig. 1. Theoretical effect of the cell size in the thermal conductivity by conduction of a PMMA-based nanocellular polymer, according to equation (5), for relative densities of $0.15,0.10$, and 0.05 .

distribution is calculated using a correction that takes into consideration the relative volumes occupied by each type of cell (details can be found elsewhere [42] and in section 4.3). As the two populations of Fig. 2.a are monodisperse, only two different cell sizes appear in the histogram.

The system of Fig. 2.a has micrometric cells of 5 microns of cell size, representing more than the $30 \%$ of the volume of the sample. However, there are more than 1000 nanometric pores per microcellular one. Then, when calculating the average cell size, the high number of nanocellular pores (with a diameter of $200 \mathrm{~nm}$ ) is predominant, given an average cell size of around $205 \mathrm{~nm}$. Assuming a relative density of 0.2 , the theoretical conductivity based only on the average cell size is $52.1 \mathrm{~mW} / \mathrm{mK}$ (obtained from equation (5)). In this calculus, the polymer matrix was assumed to be PMMA with a thermal conductivity of the solid phase of $211.7 \mathrm{~mW} / \mathrm{mK}$, and the $g$ factor was considered to be equal to 1 for this initial estimation.

Two basic approximations can be used to calculate the thermal conductivity of a two-phase system like that shown in Fig. 2.a using the common analogy of an electric circuit: the series and the parallel model (equations (6) and (7) respectively, where $\lambda_{i}$ represents the thermal conductivity of the $i$ phase ( $i=1$ or 2 ) and $V_{i}$ is the volume fraction of each of the components). The circuit analogy is a common way to compute the properties of two-phase systems such as a cellular polymer $[39,43]$.

$\lambda_{t}=\sum_{i=1,2} V_{i} \lambda_{i}$

$\frac{1}{\lambda_{t}}=\sum_{i=1,2} \frac{V_{i}}{\lambda_{i}}$

The series model maximizes the interaction between the two phases, whereas the parallel model minimizes the effect of the dispersed phase $[44,45]$. These models are commonly used to predict the conductivity of multi-phase systems, such as polymer composites or sandwich panels [46]. They can also be applied to systems like that schematized in Fig. 2.a. For that particular system, $\lambda_{1}$ would be the thermal conductivity of a microcellular material with cell size 5 microns, $\lambda_{2}$ the thermal conductivity of a nanocellular material with a cell size of $200 \mathrm{~nm}$ and $V_{1}$ and $V_{2}$ the volume fractions occupied by each population of cells (30\% and $70 \%$ in this example). With this approach, and using for instance the series model, the theoretical prediction of the conductivity is $55.4 \mathrm{~mW} / \mathrm{mK}, 6 \%$ higher than the value calculated using only the average cell size.

Based on this simple idea, we can enlarge the model for any bimodal 
a)
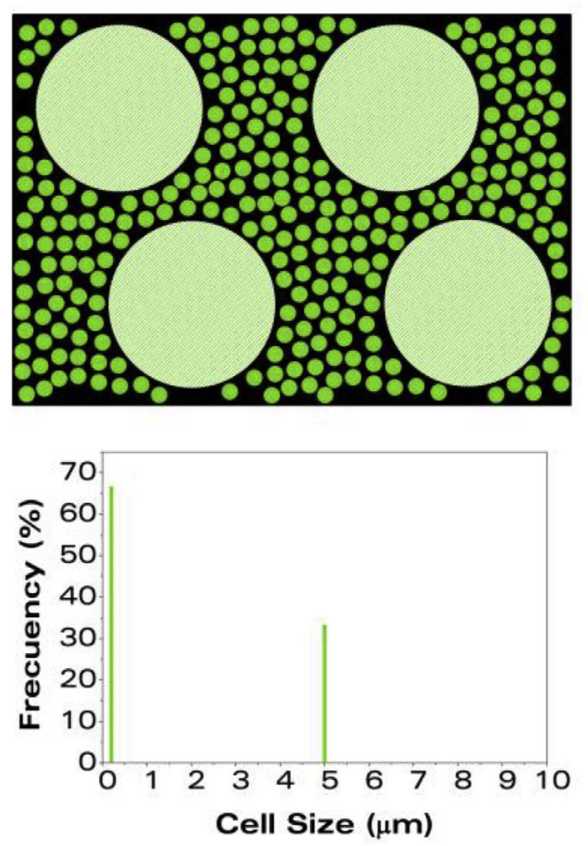

b)
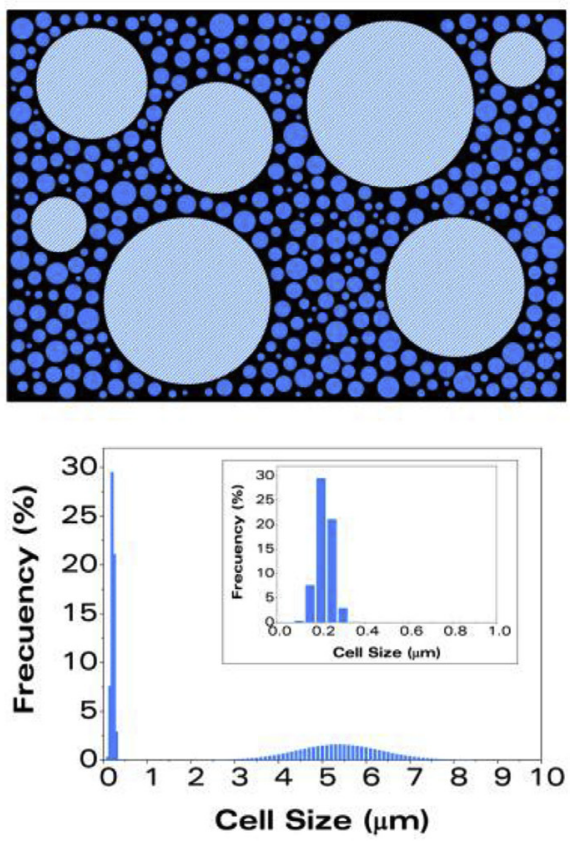

Fig. 2. Schematic representation and cell size distribution (corrected with the volume) of bimodal cellular structures: a) bimodal system with a microcellular and a nanocellular population, both monodisperse, and b) bimodal system with a microcellular and a nanocellular population, with a certain width in the cell size distributions of both micro and nanometric cells. system in which the cell size distributions have a certain width (Fig. 2.b).

Combining equation (5) with equations (6) and (7), we established the general equations for the models proposed in this work: the series model (equations (8) and (9)) and the parallel model (equations (10) and (11)). For the models, the volume fraction occupied by each class of cell size is taken into consideration, $f_{x_{i}}$ (see section 4.3 for more details about how to calculate it), and also the thermal conductivity for the corresponding cell size, $\lambda_{x_{i}}$. A distinction between micro and nanometric cells is also considered in the model. For cell sizes smaller than 7 microns [41], Knudsen correction is used for calculating the contribution of the gas phase (equations (9) and (11)). Therefore, for cell sizes higher than this threshold, no effect of the cell size is included. In addition, the structural factor $g$ in the contribution of the solid phase is assumed to be potentially different for nano $\left(g_{n}\right)$ and microcellular $\left(g_{m}\right)$ structures. This assumption is based on the intrinsic structural differences between a micrometric cell wall and a nanoporous one (with cell wall thickness in the range of $20 \mathrm{~nm}$ [47]). The reduction of the cell wall thickness to the nanoscale can induce a tortuosity effect that might reduce the $g$ factor, as reported by Notario et al. [12]. In addition, Ma et al. [48] showed that in solid films with nanometric thickness, such as the cell walls in a nanocellular polymer, the thermal conductivity is reduced when the thickness size is reduced, that is, that a strong confinement effect can lead to a reduction in the thermal conductivity. For all these reasons, we have assumed the $g$ factor being dependent on the cellular structure. This assumption has been supported with electrical conductivity measurements (see Supplementary Information). See section 5.1 for a more detailed discussion of the values of $g$.

SERIES: $\lambda_{t}=\sum_{x_{i}} f_{x_{i}} \lambda_{x_{i}}$

$\lambda_{t}=\sum_{x_{i}=0}^{7} f_{x_{i}}\left(\frac{\lambda_{g_{0}}^{\prime}\left(1-\rho_{r}\right)}{1+\frac{2 \beta l_{g}}{x_{i}}}+g_{n} \lambda_{s}^{\prime} \rho_{r}\right)+\sum_{x_{i}>7} f_{x_{i}}\left(\lambda_{g_{0}}^{\prime}\left(1-\rho_{r}\right)+g_{m} \lambda_{s}^{\prime} \rho_{r}\right)$

PARALLEL: $\frac{1}{\lambda_{t}}=\sum_{x_{i}} \frac{f_{x_{i}}}{\lambda_{x_{i}}}$

$$
\frac{1}{\lambda_{t}}=\sum_{x_{i}=0}^{7} \frac{f_{x_{i}}}{\frac{\lambda_{g_{0}^{\prime}\left(1-\rho_{r}\right)}}{1+\frac{2 \beta l g}{x_{i}}}+g_{n} \lambda_{s}^{\prime} \rho_{r}}+\sum_{x_{i}>7} \frac{f_{x_{i}}}{\lambda_{g_{0}}^{\prime}\left(1-\rho_{r}\right)+g_{m} \lambda_{s}^{\prime} \rho_{r}}
$$

In summary, the main hypothesis of the model proposed in this work to evaluate the heat transfer by conduction in a bimodal nanocellular material are the following:

- The structure presents a bimodal cellular structure with micro and nanometric cells characterized by a cell size distribution.

- Only conduction mechanisms are considered, so this model is valid as long as the density of the materials is high enough to neglect radiation $\left(\rho_{r}>0.25\right)$.

- The conduction through the gas phase is different for the micro and the nanometric cells, the last presenting Knudsen effect.

- The conduction through the solid phase is different for the micro and the nanometric cells. The differences are included in the structural factor $g$. For the microcellular population, $g_{m}$ takes a value of 1 , whereas for the nanocellular population the value, $g_{n}$, is calculated as a function of the relative density.

- o The calculation of the factor $g_{n}$ is performed using $100 \%$ nanocellular materials with different densities.

-o The results were supported with electrical conductivity measurements.

-o Out of the density range analyzed there are not experimental evidence about the value of this factor. Then, and for illustrative purposes when the model is introduced, a value of $g=1$ was considered.

- Each cell size of the cell size distribution contributes differently to the total conductivity by conduction, and its contribution is given by its corresponding volume fraction.

- To add all the contributions, two approaches based on a circuit analogy have been used: series and parallel, resulting in two versions of this model.

Fig. 3 shows the effect of the volume fraction of nanometric cells on the thermal conductivity due to the conduction using the series and the parallel model proposed in this work, for a bimodal system such as that shown of Fig. 2.b. For this particular example, the two distributions are 

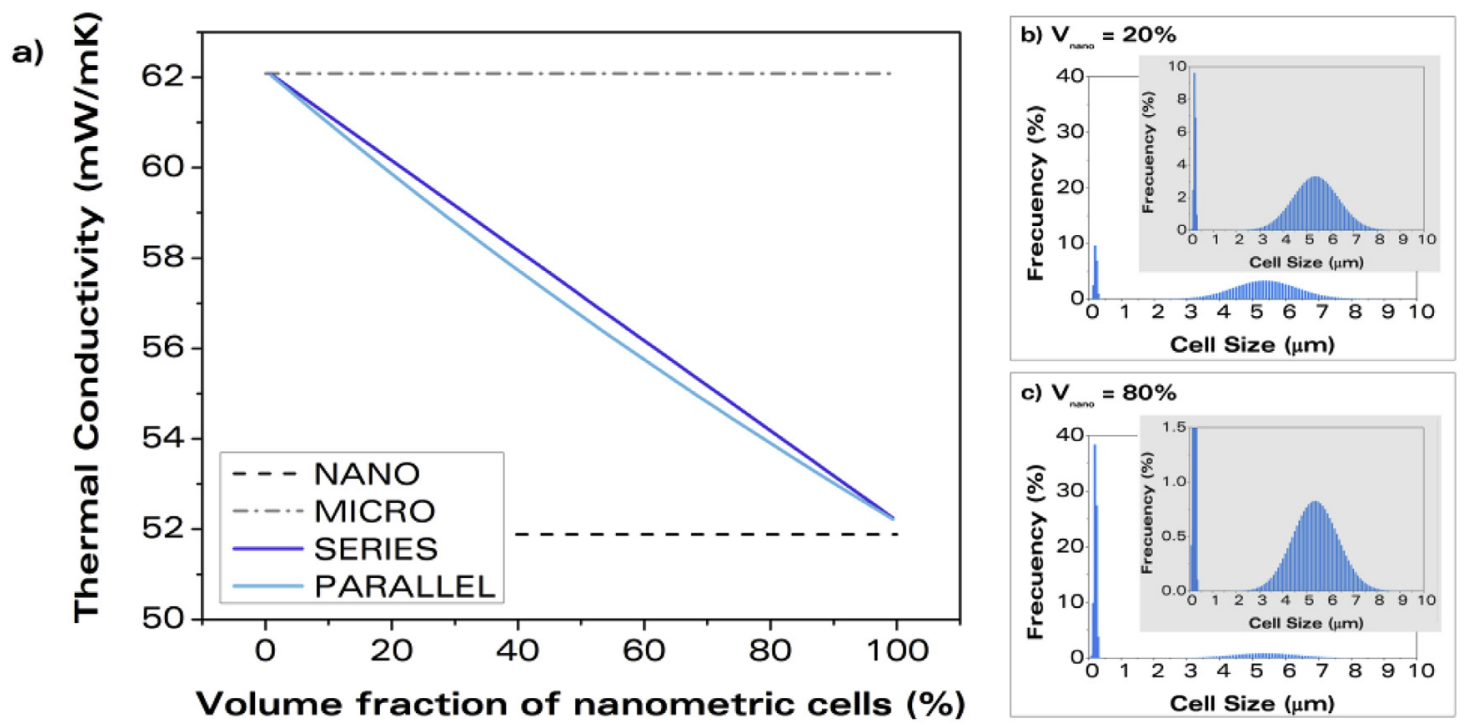

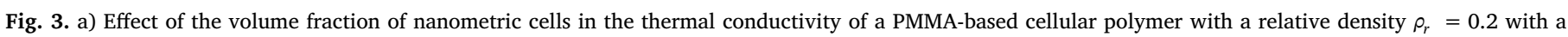

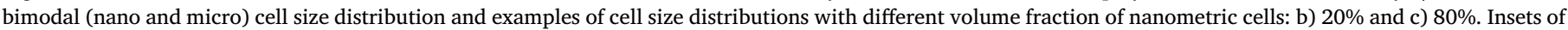
figures b) and c) show in detail the cell size distribution of the microcellular region.

Gaussian functions, with an average cell size of $200 \mathrm{~nm}$ and 5 microns and width of the distributions of $40 \mathrm{~nm}$ and 1 micron, respectively. That is, the two distributions present the same ratio width/cell size $(S D / \phi=0.2)$. The total relative density was assumed to be 0.2 and the structural factor of both micro and nanometric cells are considered as 1 . These values have been calculated using equations (9) and (11). In Fig. 3, two additional horizontal lines are plotted together with the predictions of the model: the thermal conductivity of a nanocellular polymer with $200 \mathrm{~nm}$ of cell size (named as "NANO") and a microcellular material with 5 microns of cell size (referred as "MICRO") with the same densities. The polymer matrix was assumed to be PMMA with a thermal conductivity of the solid phase of $211.7 \mathrm{~mW} / \mathrm{mK}$ and the $g$ factors were considered equal to 1 for simplicity. It is observed that both parallel and series model moved from the microcellular behaviour when the volume of nanometric cells is small, to the nanocellular line for very a large volume of nanometric cells. Even at $100 \%$ of nanometric cells, the models do not cross the nanocellular prediction, since they take into account the width of the cell size distribution of the nanocells and the nanocellular line does not. Fig. 3 also shows that the parallel model predicts smaller conductivities than the series one. Then, this model minimizes the effect of the micrometric cells in the bimodal structure.

\section{Experimental}

\subsection{Materials}

PMMA V825T was kindly supplied by ALTUGLAS ${ }^{\circledR}$ International. Poly(methyl methacrylate)-poly(butyl acrylate)-poly(methyl methacrylate) (MAM) block copolymer Nanostrength M53 was kindly supplied by Arkema Company (France). Sepiolites modified with a quaternary ammonium salt $[49,50]$ were provided by Tolsa S.A (Spain). Medical grade carbon dioxide $\left(\mathrm{CO}_{2}\right)$ ( $99.9 \%$ purity) was used as the blowing agent for the gas dissolution foaming experiments.

In this work, two different systems able to produce bimodal structures with nanometric cells are analyzed: a blend of PMMA and MAM and a blend of PMMA with sepiolites. Blends in the proportions of Table 1 were produced by extrusion using a twin-screw extruder model COLLIN TEACH-LINE ZK 25T, with L/D of 24 and screw diameter of $25 \mathrm{~mm}$, with a temperature profile set from $160^{\circ} \mathrm{C}$ to $200{ }^{\circ} \mathrm{C}$, and the screw speed equal to $40 \mathrm{rpm}$. The extruded materials were extruded
Table 1

Summary of the material systems used in this work.

\begin{tabular}{lll}
\hline System & Second phase & $\begin{array}{l}\text { Second phase amount } \\
\text { (wt\%) }\end{array}$ \\
\hline PMMA & - & - \\
PMMA/MAM & MAM Nanostrength M53 & 0.05 \\
PMMA/SEP & $\begin{array}{l}\text { Sepiolite modified with a quaternary } \\
\text { ammonium salt }\end{array}$ & 5 \\
\hline
\end{tabular}

again at the same conditions for dispersing the MAM or the sepiolites homogeneously.

Solid sheets ( $4 \mathrm{~mm}$ thick) from the blends were produced by compression molding using a hot plate press provided by Remtex (Spain). The temperature set on the press was $250{ }^{\circ} \mathrm{C}$ and processing time was $9.5 \mathrm{~min}, 8.5$ for melting the polymer and $1 \mathrm{~min}$ more for compression under pressure (1.7 MPa). From these sheets, squares of $25 \times 25 \mathrm{~mm}^{2}$ were cut for the foaming experiments.

As-received PMMA was also compressed into $4 \mathrm{~mm}$ thick solid sheets to produce reference monomodal nanocellular materials.

\subsection{Foaming experiments}

Cellular materials for thermal conductivity characterization were produced using a two-step foaming process [51] in a high-pressure vessel (model PARR 4681) provided by Parr Instrument Company. Pressure is controlled via a pressure pump controller (model SFT-10) provided by Supercritical Fluid Technologies Inc. Temperature is provided by a clamp heater controlled with a CAL 3300 temperature controller. Foaming was carried out in a thermal bath with water.

Each system requires different foaming conditions, which are summarized in Table 2. Pure PMMA requires a high saturation pressure (31 MPa) to produce nanocellular structures [52], whereas blends with MAM and sepiolites can produce them at a lower pressure (10 MPa). Different foaming temperatures were used with the aim of producing samples with different densities for each type of material. Saturation time was $24 \mathrm{~h}$ for all the experiments.

\subsection{Characterization}

The density of the solid materials $\left(\rho_{s}\right)$ was determined with a gas 
Table 2

Summary of the foaming experiments.

\begin{tabular}{|c|c|c|c|c|c|}
\hline System & Saturation Pressure (MPa) & Saturation Temperature $\left({ }^{\circ} \mathrm{C}\right)$ & Pressure Drop Rate (MPa/s) & Foaming Temperatures $\left({ }^{\circ} \mathrm{C}\right)$ & Foaming Time (min) \\
\hline PMMA & 31 & 25 & $100 \mathrm{MPa} / \mathrm{s}$ & $60 / 80 / 110$ & 1 \\
\hline PMMA/MAM & 10 & 25 & $15 \mathrm{MPa} / \mathrm{s}$ & $80 / 100$ & 1.5 \\
\hline PMMA/SEP & 10 & 25 & $15 \mathrm{MPa} / \mathrm{s}$ & $80 / 100$ & 1 \\
\hline
\end{tabular}

pycnometer (Mod. AccuPyc II 1340, Micromeritics) and the density of the cellular samples $(\rho)$ was measured using a density determination kit for an AT261 Mettler-Toledo based on Archimedes' principle. Before measuring the density, the solid skin of these foamed samples was removed out with a polisher (model LaboPOl2-LaboForce3, Struers) by removing at least $200 \mu \mathrm{m}$ of each side. Relative density was calculated as the ratio $\rho_{r}=\rho / \rho_{s}$.

The cellular structure was characterized using SEM images from an ESEM Scanning Electron Microscope (QUANTA 200 FEG). A specific software based on ImageJ/FIJI [53] was used for this purpose. Averages cell sizes and cell nucleation density (based on Kumar's theoretical approach [51]) are calculated using image analysis. The cell nucleation density of the bimodal structures needs to be carefully calculated since micro and nanometric pores cannot be quantified in the same image. A detailed explanation about this procedure is given in the Supplementary Information.

The cell size distribution in the different cellular materials was also determined. Then, a correction that takes into account the area occupied by each class of cells is applied. This correction consists of multiplying the number of cells of a given diameter $\left(n_{\text {cells }, x}\right.$, where $x$ is the cell diameter) times the surface of the cell (that is, times its radius square and $\pi$ ). Equation (12) [42] gives the formula to calculate the frequency relative to the surface for each cell size $x$ :

Frequency relative to the surface $f_{x}(x)=100 \frac{n_{\text {cells }, x} \pi\left(\frac{x}{2}\right)^{2}}{\sum_{x_{i}} n_{\text {cells }, x_{i}} \pi\left(\frac{x_{i}}{2}\right)^{2}}$

This correction is needed for accounting for the size of each cell and the corresponding area (or volume, as the surface ratio should be equal to the volume ratio when representative surfaces are analyzed, according to stereology $[46,47]$ ) occupied by each cell size. This is of extreme importance in bimodal cellular structures, with cells in the micro and the nanoscale, since for these systems a standard cell size distribution in which the number of cells for a given size is represented, neglects the contribution of microcells. Furthermore, the relative volume occupied by the population of nanometric cells has been calculated by measuring the area occupied by the micrometric cells (cell size higher than 1 micron) in the SEM images $A_{m}$ and the total area of the image, $A_{t}$, according to Equation (13).

Volume fraction nanometric cells $\mathrm{V}_{\text {nano }}(\%)=100\left(\frac{A_{t}-A_{m}}{A_{t}}\right)$

Based on this volume fraction, it is interesting to estimate the relative density of the cellular material without taking into account the microcellular pores. For this calculus, it will be assumed that the gas inside the pores is weightless. Then, the relative density in the nanocellular region can be calculated from the total relative density and the volume fraction of nanocellular pores according to (14).

$\rho_{r, \text { nano }}=\frac{\rho_{r}}{V_{\text {nano }}}$

Finally, the thermal conductivity of the cellular materials was determined by the Transient Plane Source (TPS) [54] technique using a thermal conductivimeter TPS $2500 \mathrm{~S}$ (Hotdisk). The TPS is a standard technique for the thermal properties characterization of different materials, including PMMA-based micro and nanocellular materials [12]. Measurements were carried out with a TPS sensor of radius $3.189 \mathrm{~mm}$.
Before measuring, all the samples were dried in vacuum at $50{ }^{\circ} \mathrm{C}$ overnight to remove the possible moisture. Then, two samples of the same material and density were placed in the experimental set-up. The samples and the experimental set-up were allowed to reach an equilibrium temperature for $30 \mathrm{~min}$ before the beginning of the measurements. Samples were measured five times with a time span of $20 \mathrm{~min}$ to avoid temperature drift. The measurement time was $40 \mathrm{~s}$ for all samples, whereas the typical power was about $7-9 \mathrm{~mW}$ for the cellular samples and $19-20 \mathrm{~mW}$ for the solid materials.

All the samples for thermal conductivity measurements were analyzed using X-ray radiography to ensure their homogeneity and the lack of internal defects [12].

\section{Results and discussion: validation of the model}

\subsection{Determination of the structural factor $\mathbf{g}$ for nanocellular materials}

As aforementioned, the structural factor $g$ modulating the conductivity of the solid phase is known to be close to 1 for microcellular materials with medium high/density (0.3-0.6) [34] and ranging 0.8-1 for nanocellular polymers [12] with medium high/density (0.4-0.65). To determine the value of $g$ for nanocellular materials in the range of densities used in this work, the thermal conductivity of three different monomodal nanocellular materials based on PMMA was determined experimentally and compared with the theoretical predictions of the series model (equation (9)) for different $g$ values (Fig. 4.a). The parallel model provides very similar results. These materials based on PMMA have an average cell size of $220 \mathrm{~nm}$ [47]. It is observed that, at high relative densities, the best fitting is obtained for $g$ smaller than 0.9. Meanwhile, at a medium density, this factor is close to 0.95 , and it increases at lower densities. To determine the structural factor as a function of the relative density, a linear fit between the relative density and the $g$ factor for the three materials is calculated (Fig. 4.b).

The structural factor $g$ is usually related with both the tortuosity of the material and the possible changes in the conductivity of the solid phase [12]. It is important to determine whether this adjustment of the $g$ factor is only related with structural issues and not with other possible effects like a radiation contribution. Regarding the model, it is also necessary to check if the variations of the $g$ factor depend on the density for the bimodal materials in the same way it does for the pure nanocellular PMMA. This idea was evaluated by studying the electrical conductivity of the samples at medium-high frequencies [55] (Supplementary Information). It was checked that this change in the $g$ factor is only related to structural modifications, and it was also proved that bimodal materials behave in the same way as the pure nanocellular PMMA (see Supplementary Information for more details). Then, it is justified to use the same $g$ values calculated for PMMA at any density and detailed in the previous paragraph when calculating the thermal conductivity of bimodal materials.

\subsection{System 1: bimodal micro and nanocellular PMMA/MAM}

Fig. 5 shows the cellular structure of the materials produced with the blend PMMA/MAM at different foaming temperatures. Bimodal structures, with micro and nanocellular pores, are observed regardless of the foaming conditions. Table 3 summarizes the main characteristic of these cellular materials. It is observed that $85 \%$ of the volume is 

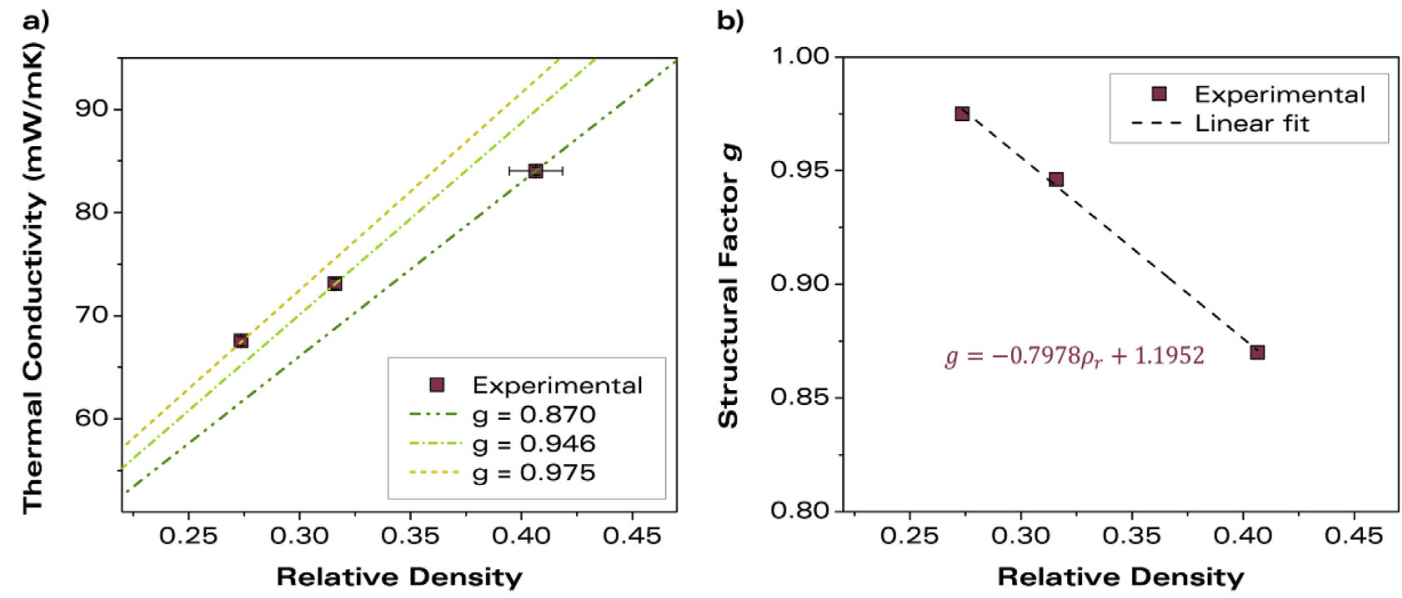

Fig. 4. a) Thermal conductivity of the materials based on PMMA: experimental data points and models with different $g$ values, and b) linear fit between the structural factor $g$ and the relative density.

occupied by nanometric cells, with cells ranging $260-280 \mathrm{~nm}$. Regarding the microcellular population, it is very heterogeneous, with cells of around 2 microns.

Fig. 6 includes the experimental thermal conductivity of these three materials as a function of the relative density, together with the predictions of the models (series and parallel) proposed in this work. In the theoretical calculations, the structural factor in the nanocellular region, $g_{n}$, was considered to vary with density as shown in Fig. 4.a and calculated according to the linear fit shown in Fig. 4.b (section 5.1). The thermal conductivity of the solid PMMA/MAM material was determined to be equal to $211.3 \mathrm{~mW} / \mathrm{mK}$, which is very similar to that of the pure PMMA. To gain a better understanding of the results provided by the model, three additional theoretical estimations have been included in Fig. 6. First, the thermal conductivity of a $100 \%$ nanocellular material (named as "NANO") with the density of the nanocellular part (equation (14)) and the cell size of the nanometric region, according to the data of Table 3. If the experimental conductivity would be the same as the theoretical one in the nanocellular region, this will imply that the
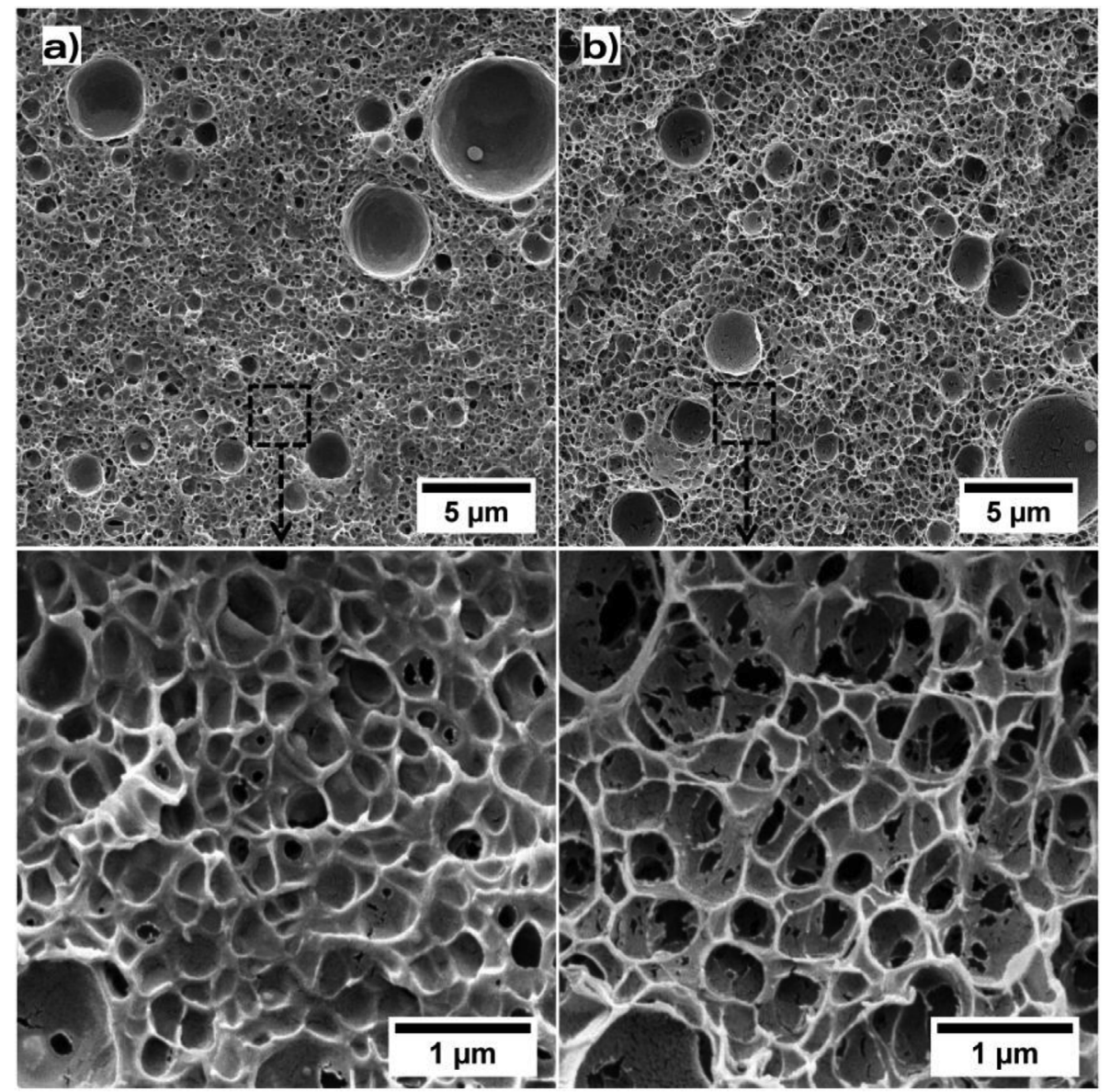

Fig. 5. SEM micrographs of the bim odal cellular materials produced with the system PMMA/MAM, foamed at a) $80^{\circ} \mathrm{C}$ and b) $100^{\circ} \mathrm{C}$. The second row corresponds to zoomed images of the first row. 
Table 3

Cellular structure characteristics of the samples based on PMMA/MAM.

\begin{tabular}{|c|c|c|c|c|c|c|}
\hline $\begin{array}{l}\text { Foaming } \\
\text { Temperature }\left({ }^{\circ} \mathrm{C}\right)\end{array}$ & $\begin{array}{l}\text { Relative } \\
\text { Density }\end{array}$ & $\mathrm{V}_{\text {nano }}(\%)$ & $\begin{array}{l}\text { Relative } \\
\text { Density NANO }\end{array}$ & Cell Nucleation Density (nuclei $/ \mathrm{cm}^{3}$ ) & Cell Size MICRO $(\mu \mathrm{m})$ & Cell Size NANO (nm) \\
\hline 80 & 0.35 & 85 & 0.41 & $5.5 \cdot 10^{13}$ & $2.2 \pm 2.1$ & $258 \pm 134$ \\
\hline 100 & 0.27 & 86 & 0.32 & $4.7 \cdot 10^{13}$ & $2.1 \pm 1.7$ & $276 \pm 152$ \\
\hline
\end{tabular}

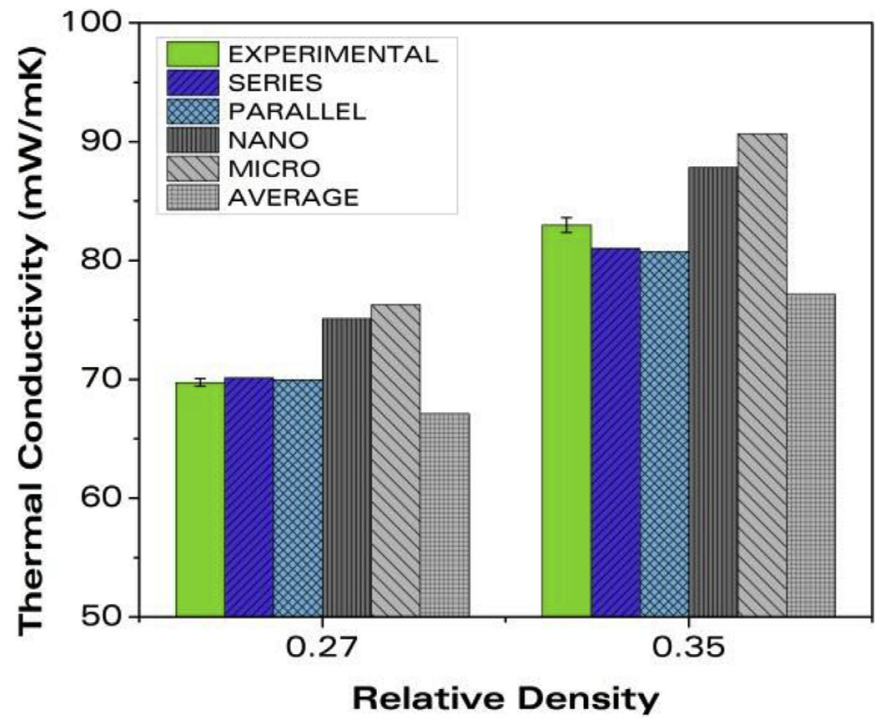

Fig. 6. Thermal conductivity of the materials based on PMMA/MAM: experimental values and theoretical predictions.

microcellular pores are not contributing to the heat transfer. That is, that conduction in the gas phase is taking place throughout the nanocellular region and the micrometric pores are isolated. On the other hand, the thermal conductivity of a purely microcellular material was also calculated an included in Fig. 6 (bars denoted as "MICRO"). For this calculus the relative density of the whole sample was used, so the comparison is between two systems with the same density: one microcellular and the other bimodal. In the case that the experimental conductivity would approach the "MICRO" value, this will mean that the presence of the nanocellular pores does not reduce the thermal conductivity. Finally, the conventional prediction using equation (5) with the average cell size ("AVERAGE") was also included. For this calculus, the average cell size of the cell size distribution was calculated using the standard average (without taking into account the size of the cells). Given the high number of nanometric cells, the average cell size is only slightly higher to the nanocellular cell size. Then, in this case, the "AVERAGE" prediction underestimates the real thermal conductivity, as it does not consider the significant volume occupied by the micrometric cells. In the Supplementary Information there are more details about all these theoretical estimations.

It is observed that in the density range analyzed both series and parallel models provide similar predictions. Also, these predictions are close to the experimental values, with a difference of less than a $3 \%$, whereas the other predictions (of materials purely nano or microcellular) overestimate the real conductivity from a $4 \%$ to a $10 \%$. These results imply that the models proposed in this work, which take into account the contributions of the different cell sizes to the total thermal conductivity, provide the best approach to quantify the thermal conductivity by conduction of these bimodal nanocellular systems. That is, the bimodal material does not behave as a microcellular material, neither as a nanocellular material with the density of the nanocellular part. Both types of cells must be included in the theoretical calculation of the thermal conductivity, weighted with the relative volume fractions occupied by them. This is a very interesting result, showing that the presence of micrometric cells helps to reduce the conductivity by reducing the density, whereas the Knudsen effect is taking place in the nanometric cells and also contributes to decrease the conductivity.

\subsection{System 2: bimodal micro and nanocellular PMMA/SEP}

Fig. 7 shows the cellular structure of the second type of bimodal materials analyzed in this work. It is observed that the microcellular population in these PMMA/SEP samples is larger and more heterogeneous than that of PMMA/MAM. Also, the volume fraction occupied by the nanometric cells is smaller (Table 4): $70 \%$ at medium densities and only $57 \%$ in the low-density sample. Regarding the nanocellular population, cell sizes ranging $260-300 \mathrm{~nm}$ are measured. The characteristics of the cellular structure of these materials are summarized in Table 4.

The experimental thermal conductivity of the samples in Fig. 7 is displayed in Fig. 8. These values are compared with the predictions of the models proposed in this work (series and parallel). For this system, the structural factor in the nanocellular region, $g_{n}$, was considered to vary with density as in the previous section. In this case, the solid phase (PMMA/SEP nanocomposite) presents a thermal conductivity of $229.3 \mathrm{~mW} / \mathrm{mK}$. This conductivity is higher than that of the PMMA or the PMMA/MAM solids due to the addition of the sepiolites. The reference estimations for a purely nanocellular material with the density of the nanocellular region ("NANO") and a completely microcellular material ("MICRO") are also included for the sake of comparison. The prediction of equation (5) calculated with the average cell size ("AVERAGE") is also plotted in Fig. 8.

Once again, the bimodal models present the best match with the experimental results, with differences of around a $3 \%$. Microcellular materials with the same densities would have higher conductivities, of around $5-10 \%$. In the case of the prediction for a nanocellular material with the density of the nanocellular region, the overestimations are higher than $25 \%$. The prediction with the average cell size also underestimates the conductivity in more than a $6 \%$. It is observed that the results are slightly less accurate than those of the PMMA/MAM system. To further improve the model, the conductivity of the solid polymer matrix in the nanometric cell walls including nanoparticles should be studied in more detail.

The success of the models to predict the thermal conductivity of these bimodal systems show that the assumptions made to elaborate the model are accurate and necessary to predict the thermal conductivity by conduction of these systems correctly. A further step to improve the precision of the model should be to analyze the conductivity of the solid polymer matrix over all the range of densities and cell sizes.

\section{Other applications of the model}

Up to now, we have proved the validity of the models proposed in this work to predict the thermal conductivity of bimodal systems. However, it could also be used to evaluate the thermal conductivity of monomodal nanocellular materials with a wide cell size distribution, like the one shown in Fig. 9.

Fig. 10 shows the effect of the ratio width/cell size $(S D / \phi)$ for a nanocellular material with an average cell size of $200 \mathrm{~nm}$ and a relative density of 0.1 . The horizontal line marked as "NANO" represents the prediction of the thermal conductivity by conduction of this system 


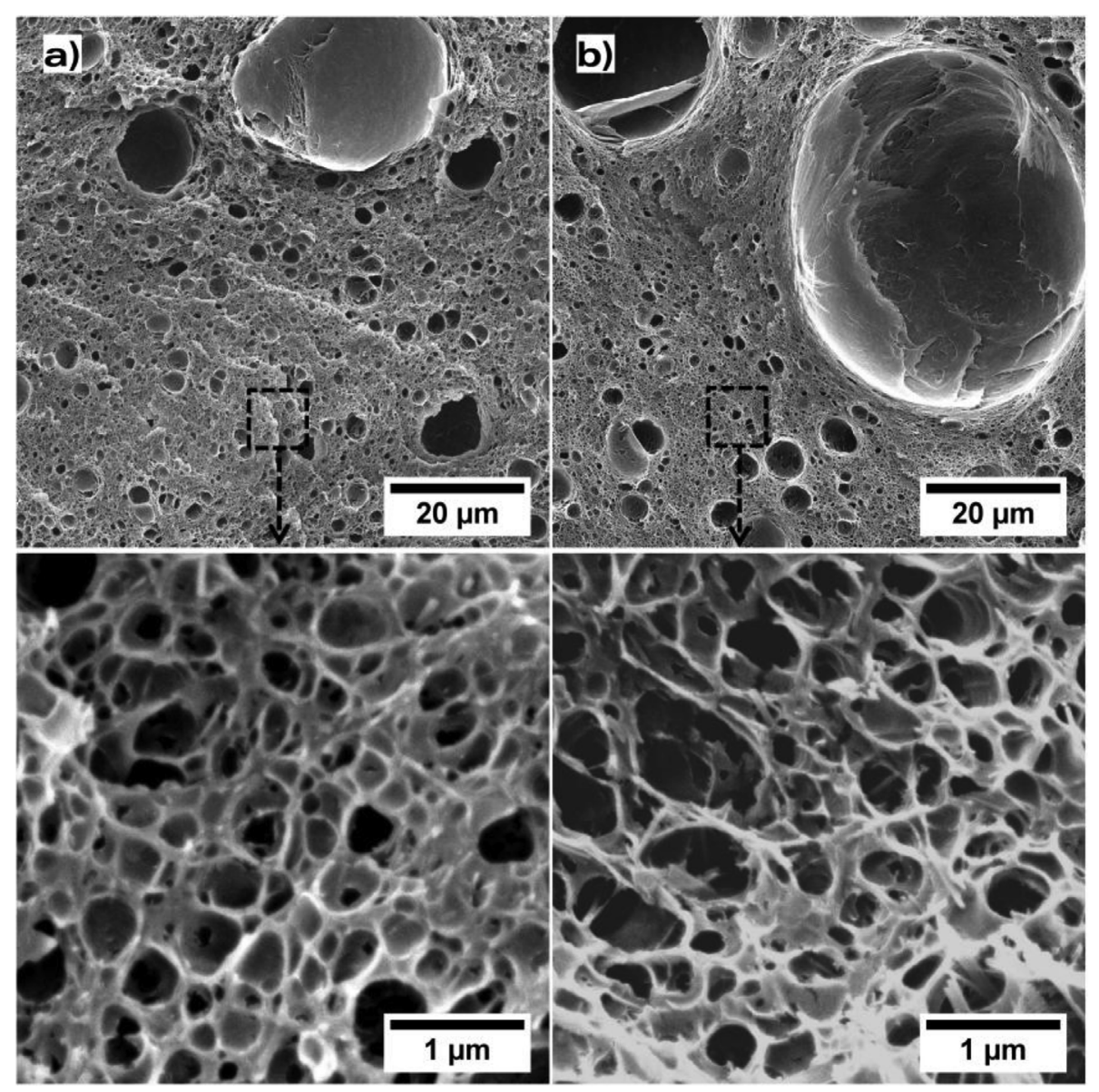

Fig. 7. SEM micrographs of the bimodal cellular materials produced with the system PMMA/SEP, foamed at a) $80^{\circ} \mathrm{C}$ and b) $100^{\circ} \mathrm{C}$. The second row corresponds to zoomed images of the first row.

Table 4

Cellular structure characteristics of the samples based on PMMA/SEP.

\begin{tabular}{|c|c|c|c|c|c|c|}
\hline Foaming Temperature $\left({ }^{\circ} \mathrm{C}\right)$ & Relative Density & $\mathrm{V}_{\text {nano }}(\%)$ & Relative Density NANO & Cell Nucleation Density (nuclei/ $\mathrm{cm}^{3}$ ) & Cell Size MICRO $(\mu \mathrm{m})$ & Cell Size NANO (nm) \\
\hline 80 & 0.38 & 70 & 0.55 & $3.5 \cdot 10^{13}$ & $2.9 \pm 3.0$ & $260 \pm 140$ \\
\hline 100 & 0.29 & 57 & 0.50 & $1.6 \cdot 10^{13}$ & $2.1 \pm 1.7$ & $296 \pm 182$ \\
\hline
\end{tabular}

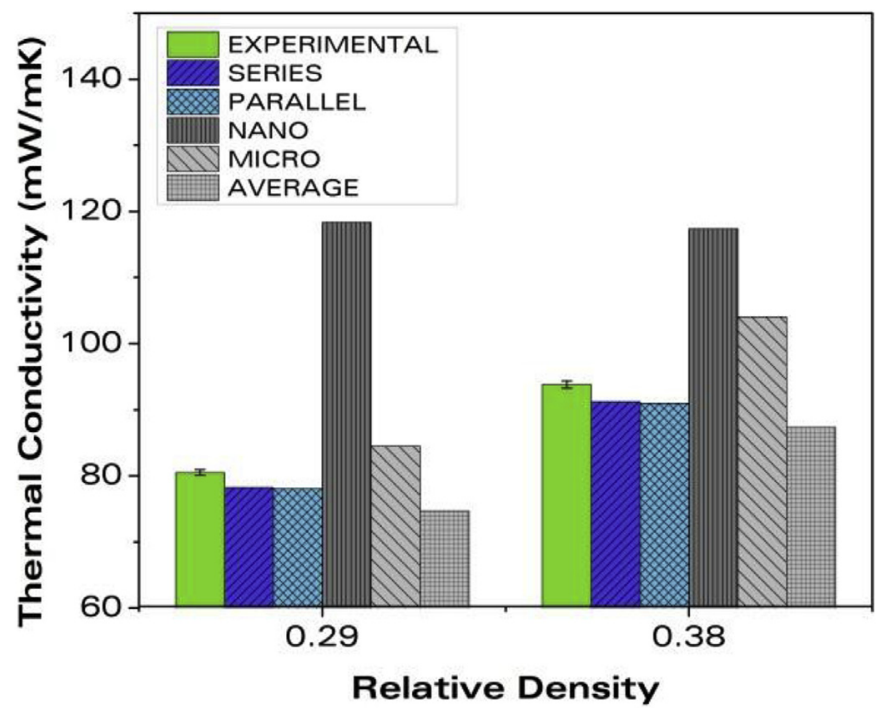

Fig. 8. Thermal conductivity of the materials based on PMMA/SEP: experimental values and theoretical predictions. without including the effect of the width of the cell size distribution. For low values of $S D / \phi$, up to 0.1 , both series and parallel model predict the same thermal conductivity of a model with a perfectly monodisperse cell size distribution. As $S D / \phi$ grows, the thermal conductivity increases, as the larger cells of the distribution start to play a role. For a value of $S D / \phi=0.5$, that is, a width of $100 \mathrm{~nm}$ with an average cell size of $200 \mathrm{~nm}$, a difference of almost $1.5 \mathrm{~mW} / \mathrm{mK}$ is predicted, that is, an increase of a $4.8 \%$ in the conductivity. Values of $S D / \phi$ of 0.5 and higher are usually detected in nanocellular materials $[47,56,57]$, so this effect is important for the accurate prediction of the thermal conductivity of nanocellular polymers.

In addition, for lower relative densities the effect of a broad cell size distribution would be even more evident, as the gas contribution is higher. Fig. 11 represents the percentage of increase in the thermal conductivity by conduction between the classic equation (equation (5)) with the average cell size and the model of this work including the effect of the cell size distribution, as a function of both the relative density and $S D / \phi$, in the range of low densities, for the series and the parallel models. The average cell size used in Fig. 11 was $200 \mathrm{~nm}$. For instance, at a relative density of 0.05 , a system with $S D / \phi=0.5$ would have a theoretical conductivity by conduction around $8-10 \%$ higher than that predicted using only the average cell size. Therefore, this 

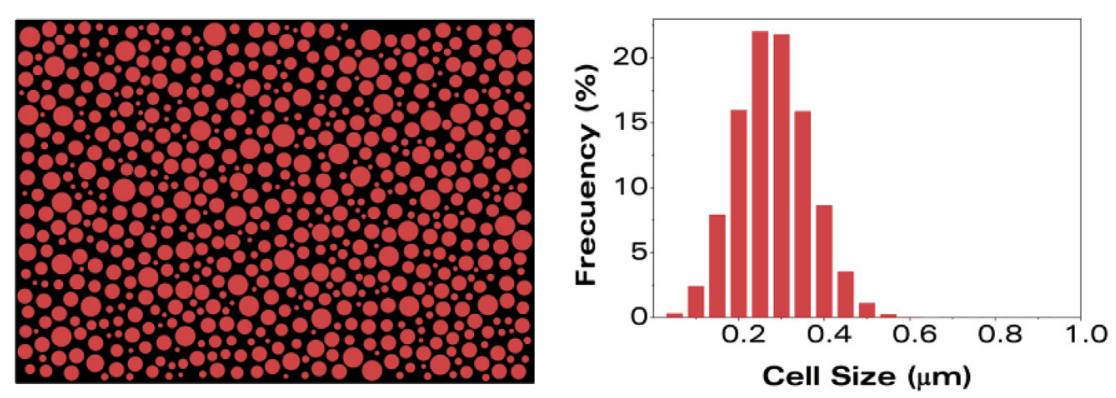

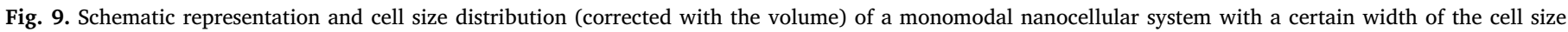
distribution.

effect must be taken into consideration when predicting the thermal conductivity of low-density nanocellular materials.

\section{Conclusions}

In this work, a new model to predict the heat transfer by conduction of bimodal cellular structures with micro and nanometric cell sizes is presented and validated. This model analyzes the conduction mechanisms both through the solid and gas phases and takes into account the volume occupied by each cell size and the Knudsen effect.

The model is based on a circuit analogy and has two different versions: series model, and parallel model. The model differentiates between nanometric cells, that should present Knudsen effect, and micrometric cells, in which this effect does not occur. Also, the structural factor modulating the contribution of the solid phase is also set as a variable that may change between micro and nanocellular materials. The values of these factor in the range of densities under study have been found by thermal and electrical conductivity measurements. The two models predict that the conductivity of a bimodal system would depend strongly on the volume fraction occupied by the nanometric cells. On the other hand, both series and parallel models provide very similar predictions, the parallel prediction being slightly smaller as this model minimizes the effect of the micrometric cells.

The model has been validated by comparing the predictions with the experimental conductivities of two bimodal systems based on PMMA: one with a block-copolymer (MAM) and one with nanoparticles (sepiolites). In both cases, the models proposed in this work provide better estimations of the conductivity than considering the material totally micro or nanocellular. Therefore, it is proved that the hypotheses of the model are valid and necessary to calculate the thermal conductivity of bimodal nanocellular materials. Moreover, it is shown that bimodal nanocellular materials could be interesting from a practical point of view since the presence of microcellular pores allows reducing the density and thermal conductivity by conduction through the solid phase, while nanometric cells contribute to reducing the conductivity through the gas phase.

In addition, we propose that this model can also be used to predict the thermal conductivity of monomodal nanocellular materials with a wide cell size distribution. The model shows that the width of the distribution strongly affects the thermal conductivity, increasing the value predicted considering only the average cell size. This effect is even more relevant at low densities. Therefore, our model could also be helpful to calculate the thermal conductivity by conduction of nanocellular materials with low density and a wide cell size distribution.

\section{Acknowledgments}

Financial assistance from MINECO, FEDER, UE (MAT2015-69234R) and the Junta de Castile and Leon (VA011U16) are gratefully acknowledged. Financial support from FPU grant FPU14/02050 (V. Bernardo) from the Spanish Ministry of Education, Juan de la CiervaIncorporación grant IJCI-2016-29992 (J. Pinto) from Spanish MINECO, and Junta of Castile and Leon grant of J. Martín-de León are gratefully acknowledged. We also want to thank Arkema for supplying the a)

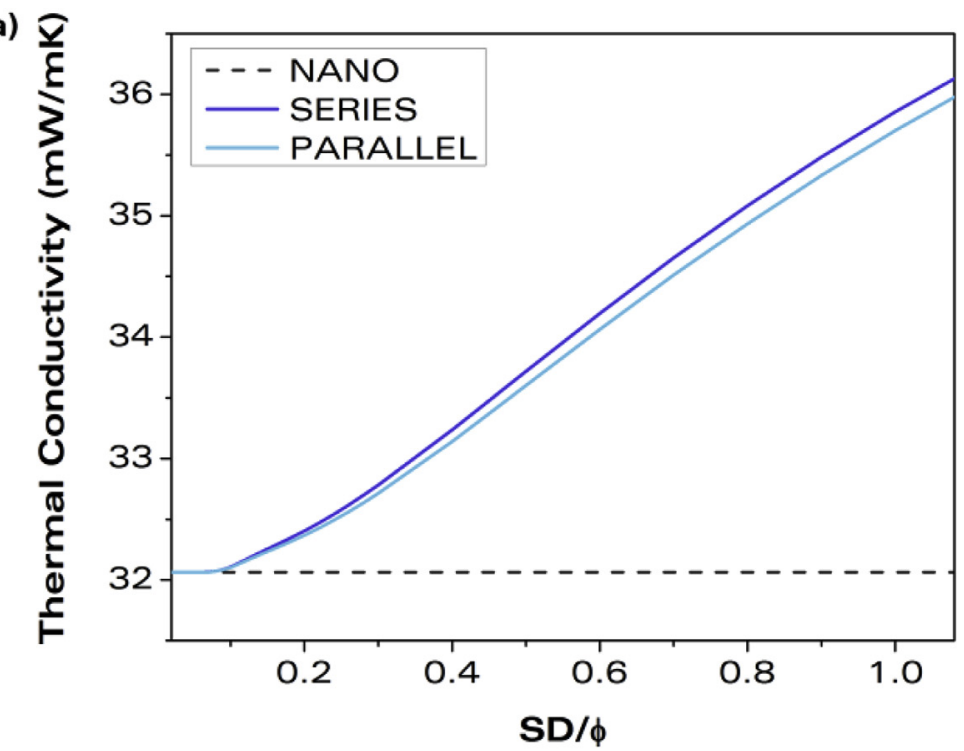

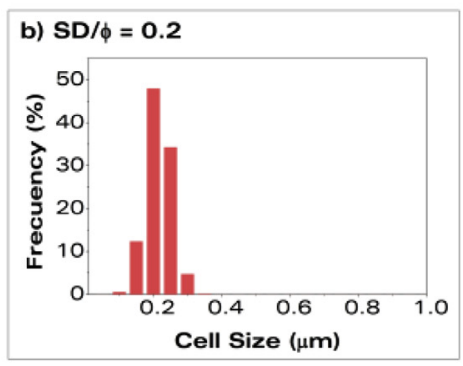

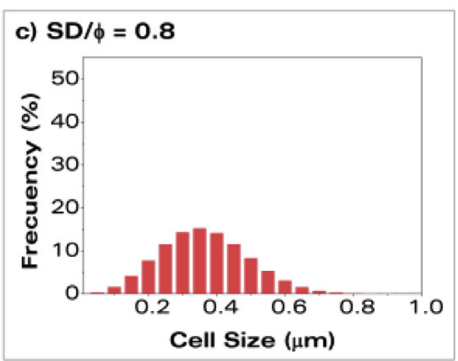

Fig. 10. a) Effect of the width of the cell size distribution in the thermal conductivity of a PMMA-based nanocellular polymer with relative density 0.1 and examples of cell size distributions for different $S D / \phi$ ratios: b) $S D / \phi=0.2$ and c) $S D / \phi=0.8$. 
a)

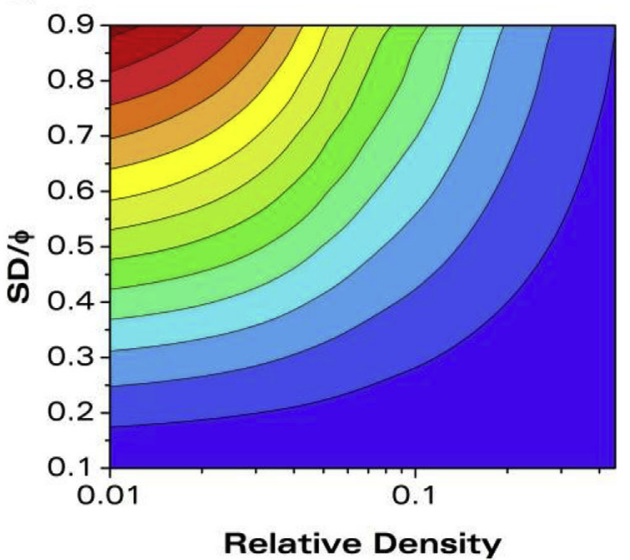

b)

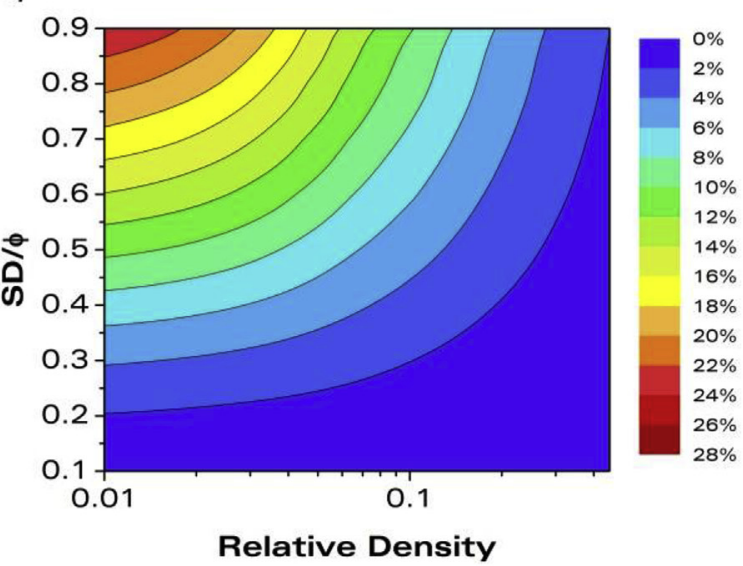

Fig. 11. Color map representing the percentage of increase of thermal conductivity compared with a model that does not include the effect of the cell size distribution as a function of the width of the cell size distribution (average cell size $200 \mathrm{~nm}$ ) and the relative density: a) series model and b) parallel model. (For interpretation of the references to colour in this figure legend, the reader is referred to the Web version of this article.)

copolymer used in this research and the company Tolsa (Madrid, Spain) for supplying the sepiolites of this study.

\section{Appendix A. Supplementary data}

Supplementary data to this article can be found online at https:// doi.org/10.1016/j.polymer.2018.11.047.

\section{References}

[1] International Energy Agency (IEA), Technology Roadmap. Energy Efficient Building Envelopes, (2013), https://doi.org/10.1007/SpringerReference 7300.

[2] P.D, United Nations Department of Economic and Social Affairs, World Population Prospects: the 2017 Revision, Methodology of the United Nations Population Estimates and Projections, (2017).

[3] M.A. Rodriguez-Perez, Crosslinked polyolefin foams: production, structure, properties, and applications, Adv. Polym. Sci. 184 (2005) 97-126, https://doi.org/10. $1007 / \mathrm{b} 136244$.

[4] D. Eaves, Handbook of Polymer Foams, United Kingdom, n.D.

[5] L.J. Gibson, M. Ashby, Cellular Solids: Structure and Properties, second ed., Cambridge University Press, 1997.

[6] B. Wicklein, A. Kocjan, G. Salazar-Alvarez, F. Carosio, G. Camino, M. Antonietti, L. Bergström, Thermally insulating and fire-retardant lightweight anisotropic foams based on nanocellulose and graphene oxide, Nat. Nanotechnol. 10 (2014) 277-283, https://doi.org/10.1038/nnano.2014.248.

[7] C.V. Vo, R.T. Fox, Assessment of hydrofluoropropenes as insulating blowing agents for extruded polystyrene foams, J. Cell. Plast. 49 (2013) 423-438, https://doi.org/ $10.1177 / 0021955 \times 13488398$.

[8] C.V. Vo, F. Bunge, J. Duffy, L. Hood, Advances in thermal insulation of extruded polystyrene foams, Cell. Polym. 30 (2011) 137-156.

[9] B. Notario, J. Pinto, M.A. Rodriguez-Perez, Nanoporous polymeric materials : a new class of materials with enhanced properties, Prog. Polym. Sci. (2016) 93-139, https://doi.org/10.1016/j.pmatsci.2016.02.002 78-79.

[10] European Commission, Horizon 2020 Work Programme 2014 - 2015 Science with and for Society Revised, (2015).

[11] J. Pinto, M. Dumon, M.A. Rodriguez-Perez, Nanoporous polymer foams from nanostructured polymer blends: preparation, characterization, and properties, in: P. Visakh, G. Markovic, D. Pasquini (Eds.), Recent Dev. Polym. Macro, Micro Nano Blends, Woodhead Publishing in Materials, 2016, pp. 237-288.

[12] B. Notario, J. Pinto, E. Solorzano, J.A. de Saja, M. Dumon, M.A. Rodriguez-Perez, Experimental validation of the Knudsen effect in nanocellular polymeric foams, Polymer (Guildf) 56 (2015) 57-67, https://doi.org/10.1016/j.polymer.2014.10. 006.

[13] L.W. Hrubesh, R.W. Pekala, Thermal properties of organic and inorganic aerogels, J. Mater. Res. 9 (1994) 731-738, https://doi.org/10.1557/JMR.1994.0731.

[14] X. Lu, R. Caps, J. Fricke, C.T. Alviso, R.W. Pekala, Correlation between structure and thermal conductivity of organic aerogels, J. Non-Cryst. Solids 188 (1995) 226-234, https://doi.org/10.1016/0022-3093(95)00191-3.

[15] L. Grassberger, K. Koch, R. Oberhoffer, A. Müller, H.F.M. Klemmer, R. Strey, Blowing agent free generation of nanoporous poly ( methylmethacrylate ) materials, Colloid Polym. Sci. 295 (2017) 379-389, https://doi.org/10.1007/s00396017-4012-1.

[16] G. Wang, J. Zhao, L.H. Mark, G. Wang, K. Yu, C. Wang, C.B. Park, G. Zhao, Ultratough and super thermal-insulation nanocellular PMMA/TPU, Chem. Eng. J. 325 (2017) 632-646, https://doi.org/10.1016/j.cej.2017.05.116.
[17] C. Forest, P. Chaumont, P. Cassagnau, B. Swoboda, P. Sonntag, Polymer nano-foams for insulating applications prepared from CO 2 foaming, Prog. Polym. Sci. 41 (2015) 122-145, https://doi.org/10.1016/j.progpolymsci.2014.07.001.

[18] S.S. Sundarram, W. Li, On thermal conductivity of micro- and nanocellular polymer foams, Polym. Eng. Sci. 53 (2013), https://doi.org/10.1002/pen.

[19] G. Wang, C. Wang, J. Zhao, G. Wang, C.B. Park, G. Zhao, Modelling of thermal transport through a nanocellular polymer foam: toward the generation of a new superinsulating material, Nanoscale 9 (2017) 5996-6009, https://doi.org/10.1039/ c7nr00327g.

[20] A.N. Paquet, K.W. Suh, Flexible Bimodal Foam Structures 5 (1988) 332,761.

[21] A.N. Paquet, Suh, Carbon black-containing bimodal foam structures and process for making, 5 (1993) 210,105.

[22] K.M. Lee, E.K. Lee, S.G. Kim, C.B. Park, H.E. Naguib, Bi-cellular foam structure of polystyrene from extrusion foaming process, J. Cell. Plast. 45 (2009) 539-553, https://doi.org/10.1177/0021955X09343632.

[23] C. Zhang, B. Zhu, D. Li, L.J. Lee, Extruded polystyrene foams with bimodal cell morphology, Polymer (Guildf). 53 (2012) 2435-2442, https://doi.org/10.1016/j. polymer.2012.04.006.

[24] K.A. Arora, A.J. Lesser, T.J. McCarthy, Preparation and characterization of microcellular polystyrene foams processed in supercritical CO2, Macromolecules 38 (1997) 446-447, https://doi.org/10.1021/ma971811z.

[25] C. Zeng, N. Hossieny, C. Zhang, B. Wang, Synthesis and processing of PMMA carbon nanotube nanocomposite foams, Polymer (Guildf) 51 (2010) 655-664, https://doi. org/10.1016/j.polymer.2009.12.032.

[26] G. Luo, X. Gu, J. Zhang, R. Zhang, Q. Shen, M. Li, L. Zhang, Microstructural, mechanical, and thermal-insulation properties of poly(methyl methacrylate)/silica aerogel bimodal cellular foams, J. Appl. Polym. Sci. 134 (2017) 1-7, https://doi. org/10.1002/app. 44434.

[27] D. Miller, V. Kumar, Fabrication of microcellular HDPE foams in a sub- critical CO 2 process, Cell. Polym. 28 (2009) 25-40.

[28] D. Schmidt, V.I. Raman, C. Egger, C. du Fresne, V. Schädler, Templated crosslinking reactions for designing nanoporous materials, Mater. Sci. Eng. C 27 (2007) 1487-1490, https://doi.org/10.1016/j.msec.2006.06.028.

[29] P. Gong, G. Wang, M.P. Tran, P. Buahom, S. Zhai, G. Li, C.B. Park, Advanced bimodal polystyrene/multi-walled carbon nanotube nanocomposite foams for thermal insulation, Carbon N. Y. 120 (2017) 1-10, https://doi.org/10.1016/j. carbon.2017.05.029.

[30] N.C. Hilyard, A. Cunningham, Low Density Cellular Plastics-Physical Basis of Behaviour, Chapman and Hall, London, 1994.

[31] M. Alvarez-Lainez, M.A. Rodríguez-Pérez, J.A. de Saja, Thermal conductivity of open-cell polyolefin foams, J. Polym. Sci., Part B: Polym. Phys. 46 (2008) 212-221, https://doi.org/10.1002/polb.

[32] R.J.J. Williams, C.M. Aldao, Thermal conductivity of plastic foams, Polym. Eng. Sci. 23 (1983) 293-298, https://doi.org/10.1002/pen.760230602.

[33] L.R. Glicksman, Heat transfer in foams, in: N.C. Hilyard, A. Cunningham (Eds.), Low Density Cell. Plast, Springer, Dordrecht, 1994, pp. 104-152, , https://doi.org/10. 1007/978-94-011-1256-7 5.

[34] M. Saadatfar, C.H. Arns, M.A. Knackstedt, T. Senden, Mechanical and transport properties of polymeric foams derived from 3D images, Colloids Surfaces A Physicochem. Eng. Asp. 263 (2005) 284-289, https://doi.org/10.1016/j.colsurfa. 2004.12.040.

[35] M. Knudsen, The Kinetic Theory of Gases, Methuen, London, 1934.

[36] S. Song, M.M. Yovanovich, F.O. Goodman, Thermal gap conductance of conforming surfaces in contact, J. Heat Tran. 115 (1993) 533-540.

[37] P. Ferkl, R. Pokorný, M. Bobák, J. Kosek, Heat transfer in one-dimensional microand nano-cellular foams, Chem. Eng. Sci. 97 (2013) 50-58, https://doi.org/10. 1016/j.ces.2013.04.018.

[38] N.G. Hadjiconstantinou, The limits of Navier-Stokes theory and kinetic extensions 
for describing small-scale gaseous hydrodynamics the limits of Navier-Stokes theory and kinetic extensions for describing small-scale gaseous hydrodynamics, Phys. Fluids 18 (2006) 111301, https://doi.org/10.1063/1.2393436.

[39] P.G. COLLISHAW, J.R.G. EVANS, An assessment of expressions for the apparent thermal-conductivity of cellular materials, J. Mater. Sci. 29 (1994) 2261-2273, https://doi.org/10.1007/BF00363413.

[40] Z. Li, C. Zhu, X. Zhao, A theoretical and numerical study on the gas-contributed thermal conductivity in aerogel, Int. J. Heat Mass Tran. 108 (2017) 1982-1990.

[41] J. Nassios, Kinetic theory of rarefied gas flows with modern applications vol. 40, (2013), p. 50.

[42] V. Bernardo, J. Martin-de León, E. Laguna-Gutiérrez, M.Á. Rodríguez-Pérez, PMMAsepiolite nanocomposites as new promising materials for the production of nanocellular polymers, Eur. Polym. J. 96 (2017) 10-26, https://doi.org/10.1016/j. eurpolymj.2017.09.002.

[43] A.G. Leach, The thermal conductivity of foams. I: models for heat conduction, J. Phys. D Appl. Phys. 26 (1993) 733-739, https://doi.org/10.1088/0022-3727/26/ 5/003.

[44] D.M. Bigg, Thermal conductivity of heterophase polymer compositions, Adv. Polym. Sci. 119 (1995) 1-29.

[45] Z. Han, A. Fina, Thermal conductivity of carbon nanotubes and their polymer nanocomposites: a review, Prog. Polym. Sci. 36 (2011) 914-944, https://doi.org/10. 1016/j.progpolymsci.2010.11.004.

[46] T. Kawasaki, S. Kawai, Thermal insulation properties of wood-based sandwich panel for use as structural insulated walls and floors, J. Wood Sci. 52 (2006) 75-83, https://doi.org/10.1007/s10086-005-0720-0.

[47] J. Martin de-Leon, V. Bernardo, M.A. Rodriguez-Perez, Low density nanocellular polymers based on PMMA produced by gas dissolution Foaming: fabrication and cellular structure characterization, Polymers (Basel) 8 (2016) 1-16, https://doi. org/10.3390/polym8070265.

[48] K. Kurabayashi, M. Asheghi, M. Touzelbaev, K.E. Goodson, Measurement of the thermal conductivity anisotropy in polyimide films, IEEE J. Microelectromechanical
Syst. 8 (1999) 180-191, https://doi.org/10.1109/84.767114.

[49] N. García, J. Guzman, E. Benito, A. Esteban-Cubillo, E. Aguilar, J. Santaren, P. Tiemblo, Surface modification of sepiolite in aqueous gels by using methoxysilanes and its impact on the nanofiber dispersion ability, Langmuir 27 (2011) 3952-3959.

[50] J. Santaren, A. Alvarez, A. Esteban-Cubillo, B. Notario, D. Velasco, M.A. Rodriguez Perez, Improving the cellular structure and thermal conductivity of PS foams by using sepiolites, Foams2012, 2012, pp. 1-5.

[51] V. Kumar, N.P. Suh, A process for making microcellular parts, Polym. Eng. Sci. 30 (1990) 1323-1329.

[52] J. Pinto, M. Dumon, M. Pedros, J. Reglero, M.A. Rodriguez-Perez, Nanocellular CO2 foaming of PMMA assisted by block copolymer nanostructuration, Chem. Eng. J. 243 (2014) 428-435, https://doi.org/10.1016/j.cej.2014.01.021.

[53] J. Pinto, E. Solorzano, M.A. Rodriguez-perez, J.A. De Saja, Characterization of the cellular structure based on user-interactive image analysis procedures, J. Cell. Plast. 49 (2013) 555-575, https://doi.org/10.1177/0021955X13503847.

[54] A. International, D 5930 - 01: Standard Test Method for Thermal Conductivity of Plastics by Means of a Transient Line-source Technique, (n.d.). doi:10.1520/ D5930-09.

[55] J. Pinto, B. Notario, R. Verdejo, M. Dumon, S. Costeux, M.A. Rodriguez-Perez, Molecular confinement of solid and gaseous phases of self-standing bulk nanoporous polymers inducing enhanced and unexpected physical properties, Polymer (Guildf) 113 (2017) 27-33, https://doi.org/10.1016/j.polymer.2017.02.046.

[56] C. Forest, P. Chaumont, P. Cassagnau, B. Swoboda, P. Sonntag, Nanofoaming of PMMA using a batch CO2 process: influence of the PMMA viscoelastic behaviour, Polymer (Guildf) 77 (2015) 1-9, https://doi.org/10.1016/j.polymer.2015.09.011.

[57] V. Bernardo, J. Martin-de Leon, E. Laguna-Gutierrez, T. Catelani, J. Pinto, A. Athanassiou, M.A. Rodriguez-Perez, Understanding the role of MAM molecular weight on the production of PMMA/MAM nanocellular polymers, Polymer (Guildf) 153 (2018) 262-270, https://doi.org/10.1016/j.polymer.2018.08.022. 